\title{
Potensi Inokulasi Jamur Trichoderma viride dan Glomus sp. Terhadap Produktivitas Capsicum annuum $\mathrm{L}$
}

\section{Potential of Trichoderma viride and Glomus sp. on Productivity of Capsicum annuum $L$.}

\author{
Santi WP ${ }^{1}$, Defiani RM ${ }^{1}$, Proborini MW $^{1}$ \\ ${ }^{1}$ Program Studi Biologi, Fakultas Matematika dan Ilmu Pengetahuan Alam, Universitas Udayana. Jl. Raya \\ Kampus UNUD, Jimbaran, Kuta Selatan, 80361, Bali, Indonesia.
}

Santi WP, Defiani RM, Proborini MW. 2019 - Potensi Inokulasi Jamur Trichoderma viride dan Glomus sp. terhadap Produktivitas Capsicum annuum L. Jurnal Mikologi Indonesia 3(2), 95-103.

\begin{abstract}
Abstrak
Cabai rawit (Capsicum annuum) merupakan komoditi pertanian yang digunakan dalam berbagai jenis produk makanan. Pemanfaatan pupuk anorganik berdampak buruk terhadap lingkungan sehingga diperlukan agen hayati, seperti Trichoderma viride dan fungi mikoriza arbuskula (FMA) untuk memperbaiki kondisi tanah. Tujuan penelitian ini mengobservasi pemberian kombinasi $T$. viride dan FMA Glomus sp. Terhadap produksi cabai rawit serta mengetahui dosis kombinasi optimum dalam meningkatkan produktivitas cabai rawit. Penelitian dilakukan di laboratorium Taksonomi Tumbuhan/Mikologi dan green house Program Studi Biologi, Fakultas MIPA, Universitas Udayana. Penelitian menggunakan Rancangan Acak Kelompok dengan lima perlakuan yaitu (A) tanah steril (Kontrol negatif); (B) tanah steril dan 50 spora Glomus sp.; (C) tanah steril dan 2 g pupuk anorganik CPN15-0$14 \mathrm{KNO}_{3}$ Merah; (D) tanah steril, $5 \mathrm{~mL}$ T. viride dan 50 spora Glomus sp.; (E) tanah steril, $10 \mathrm{~mL} \mathrm{~T}$. viride dan 50 spora Glomus sp. Setiap perlakuan memiliki lima ulangan yang terdiri dari tiga unit tanaman. Pengamatan dilakukan terhadap tinggi tanaman, jumlah buah, berat basah dan berat kering buah, berat kering tajuk, berat kering akar dan infeksi FMA. Hasil penelitian menunjukkan bahwa penambahan pupuk anorganik menghasilkan nilai tertinggi pada hampir seluruh parameter yang diamati kecuali pada persentase kolonisasi FMA. Perlakuan E menunjukkan hasil yang lebih optimum dalam produksi cabai rawit meski belum mampu menandingi pupuk anorganik.
\end{abstract}

Kata kunci - infeksi jamur-pertumbuhan cabai-produksi

\section{Abstract}

Chili (Capsicum annuum) is an agricultural commodity that are used in many food products. Inorganic fertilizer has been known for their negative impact to the environment, therefore, biological agents such as Trichoderma viride and arbuscular mycorrhizal fungi (AMF) are necessary to improve soil condition. This study aimed to observe the application of T. viride and AMF Glomus sp. and also to determine the optimum dose for productivity of C. annuum . The study was carried at the laboratories of Plant Taxonomy/Mycology and as well as the greenhouse of Biology Study Program, Faculty of Mathematics and Natural Sciences of Udayana University. The study used randomized block design that consists of five treatments, namely, (A) Sterile soil/control; (B) Sterile soil and 50 spores of Glomus sp.; (C) Sterile soil and $2 \mathrm{~g}$ inorganic fertilizer CPN15-0-14 $\mathrm{KNO}_{3}$ Red; (D) Sterile soil, $5 \mathrm{~mL}$ of T. viride and 50 spores of Glomus sp.; (E) Sterile soil, $10 \mathrm{~mL}$ of T. viride and 50 spores of Glomus sp. Each 
treatmentwas conducted by five replications, and each replication consisted of three units of plants. The observation was conducted on plant growth, number of chili fruit, fresh and dry weight of chili, dry weight of biomass, and AMF infection. The results showed that the application of $T$. viride and AMF had lower value than inorganic fertilizer in almost all parameters. Meanwhile treatment of sterile soil amended with 50 spores of Glomus sp. (B)exhibited highest value for percentage of AMF infection, and the treatment of sterile soil amended with $10 \mathrm{~mL}$ of $T$. viride and 50 spores of Glomus sp. (E) showed better productivity than the other combination.

\section{Key words - chili growth-fungal infection-production}

\section{Pendahuluan}

Cabai rawit merupakan komoditas hortikultura yang dibutuhkan untuk keperluan pelengkap bumbu atau diolah menjadi bentuk kering. Kondisi lingkungan yang tidak mendukung dapat menimbulkan serangan penyakit pada tanaman cabai yang menurunkan hasil panen sebesar 20-30\% (Warisno \& Kres 2010). Untuk meningkatkan produksi beberapa petani menggunakan alternative berbahan kimia yang dapat berakibat buruk terhadap lingkungan. Oleh sebab itu, diperlukan agen hayati sebagai alternatif yang ramah lingkungan seperti jamur Trichoderma viride dan fungi mikoriza arbuskula (FMA).

Gusnawaty dkk. (2014) menyatakan jamur Trichoderma spp. Merupakan mikroorganisme tanah yang menguntungkan tanaman. Jamur $T$. viride dapat dijumpai pada berbagai jenis tanah. Jamur ini berkembang dengan cepat dan menginfeksi perakaran tanaman. Keuntungan infeksi jamur $T$. viride adalah dapat dimanfaatkan sebagai agen biokontrol yang dapat membantu menghambat pertumbuhan organisme penyebab penyakit pada tanaman. Jamur T. viride akan berkembang disekitar permukaan dan ujung akar sehingga menghambat kontak antara perakaran tanaman dengan organism patogen di dalam tanah. Hal ini didukung oleh hasil penelitian Yudha dkk. (2016) bahwa Trichoderma spp. dapat meningkatkan pertumbuhan tanaman dan menurunkan intensitas serangan penyakit akar gada pada tanaman sawi hijau. Menurut Nadhifah dkk. (2016) jamur Trichoderma memiliki ciri berupa koloni berwarna kehijauan. Syahputra dkk. (2017) melaporkan Trichoderma memiliki bentuk koloni yang melingkar dengan batas yang jelas. Trichoderma spp. memiliki konidiofora, fialid yang pendek, dan konidia bulat berwarna hijau (Gusnawaty dkk. 2014). Hal ini juga didukung oleh Pitt \& Hocking (1997) yang menyatakan bahwa Trichoderma memiliki fialid yang bercabang-cabang dengan konidia berwarna hijau.

Menurut Schüßler \& Walker (2010) FMA adalah kelompok jamur Glomeromycota yang bersimbiosis dengan system perakaran tanaman yang terjadi di dalam tanah. Simbiosis terjadi dengan terbentuknya kolonisasi oleh mikoriza pada akar tanaman untuk memperoleh nutrisi (Musfal 2010). Mikoriza membantu penyerapan air dan nutrisi sehingga dapat membantu ketahanan tanaman terhadap kekeringan dan membantu pertumbuhan tanaman pada lingkungan yang kurang mendukung (Subiksa 2002).

Kemampuan kedua agen hayati ini dalam pencegahan infeksi penyakit dan membantu penyerapan unsur hara dapat meningkatkan kualitas tanaman sehingga dapat meningkatkan produktivitas tanaman cabai rawit. Meskipun telah banyak penelitian menyatakan bahwa jamur T. viride dan FMA Glomus sp. Dapat menjadi agen biokontrol yang baik, penelitian mengenai penggunaan kedua agen hayati ini dalam meningkatkan produksi tanaman cabai rawit masih jarang dilakukan. Oleh sebab itu, perlu dilakukan penelitian yang bertujuan untuk mengetahui pengaruh keduanya terhadap produktsi tanaman cabai rawit (C. annuum).

\section{MetodaPenelitian}

Penelitian dilakukan di Laboratorium Taksonomi Tumbuhan/Mikologi dan Green house Program Studi Biologi, Fakultas MIPA, Universitas Udayana mulai dari bulan Desember 
2018 hingga Mei 2019. Bahan utama yang digunakan penelitian meliputi benih Bintang Asia cabai rawit (C. annuum), media tanam dengan tanah berpasir (1:1), spora Glomus sp. dan biakan jamur T. viride koleksi Laboratorium Mikologi, Universitas Udayana dan $2 \mathrm{~g}$ pupuk anorganik CPN 15-0-14 KNO3 Merah cap Pak Tani.

\section{Persiapan media tanam}

Tanah berpasir (1:1) sebagai media tanam disterilisasi dengan metode kukus. Media tanam selanjutnya dipindahkan ke dalam polybag diameter $\pm 30 \mathrm{~cm}$ masing-masing sebanyak $10 \mathrm{~kg}$ dan disiram dengan air hingga kapasitas lapang. Biakan jamur T.viride usia 7 hari kemudian dipotong dengan ukuran $1 \times 1 \mathrm{~cm}$ lalu dimasukan ke dalam tabung reaksi dan dilarutkan dengan air steril sebanyak 5 dan $10 \mathrm{~mL}$. 50 butir spora Glomus sp. berasal dari rizosfer tanaman jagung yang diperoleh melalui penyaringan bertingkat dengan metode Kormanik \& Mc. Graw (1982). Spora hasil penyaringan diambil menggunakan mikropipet dan dimasukan ke dalam tube berisi air steril dan disimpan di dalam refrigerator hingga saat akan digunakan.

\section{Penyemaian dan pemeliharaan benih}

Benih cabai rawit (C.annuum) disemai pada tray semai hingga tumbuh dan memiliki 2-3 helai daun. Selanjutnya bibit dipindahkan ke dalam polybag yang telah berisi $10 \mathrm{~kg}$ media tanam dan diberi penambahan sesuai perlakuan masing-masing yaitu : A. tanah steril/kontrol, B. tanah steril dan 50 spora Glomus sp., C.tanah steril dan2 g pupuk anorganik CPN $\mathrm{KNO}_{3}$ merah, D. tanah steril,5 mL T. viride dan 50 spora Glomus sp., E. tanah steril, $10 \mathrm{~mL} \mathrm{~T}$. viride dan 50 spora Glomus sp.. Bibit dipelihara hingga berusia 120 hari dengan penyiraman sebanyak dua kali sehari dan penyiangan secara manual setiap minggu.

\section{Rancangan penelitian dan variable pengamatan}

Penelitian menggunakan Rancangan Acak Kelompok (RAK) dengan lima pengulangan dan setiap pengulangan terdiri dari tiga unit tanaman, sehingga total keseluruhan berjumlah 75 tanaman. Variabel pengamatan penelitian meliputi tinggi tanaman, jumlah buah, berat basah dan berat kering buah, berat kering tajuk dan akar, serta persentase kolonisasi AMF. Penghitungan kolonisasi menggunakan metode Kormanik \& Mc. Graw (1982) dengan modifikasi yang terdiri dari beberapa tahapan yaitu clearing, staining, dan destaining.

\section{Hasil}

\section{Tinggi tanaman}

Berdasarkan hasil penelitian pada parameter tinggi tanaman (Gambar 1) diketahui bahwa perlakuan $\mathrm{C}$ menghasilkan nilai yang paling tinggi. Perlakuan $\mathrm{C}$ menghasilkan tinggi tanaman paling tinggi yaitu $135,05 \mathrm{~cm}$ dan terendah $45,85 \mathrm{~cm}$ dihasilkan oleh perlakuan A (Kontrol).

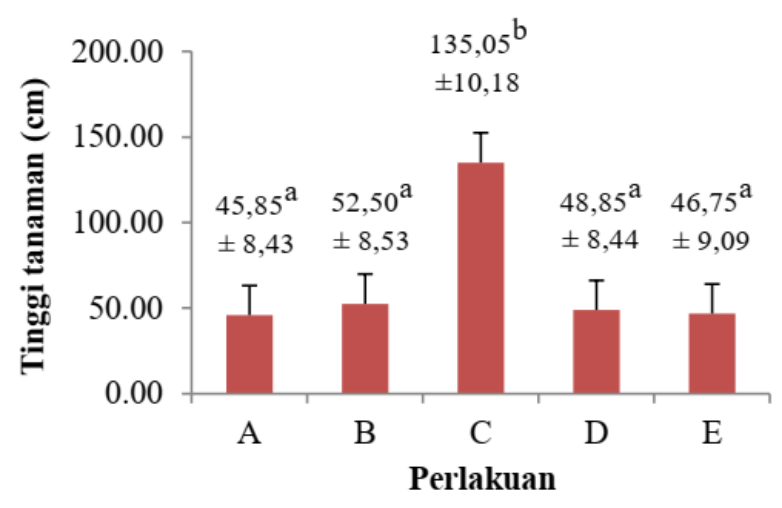

Gambar 1. Rata-rata tinggi tanaman. A. Tanah steril/kontrol. B. Tanah steril dan 50 spora Glomus sp. 
C. Tanah steril dan $2 \mathrm{~g}$ pupuk anorganik $\mathrm{CPN} \mathrm{KNO}_{3}$ Merah. D. Tanah steril, $5 \mathrm{~mL} T$. viride dan 50 spora Glomus sp. E. Tanah steril, 10mL T.viride dan 50 spora Glomus sp.

\section{Berat kering tanaman (tajuk dan akar)}

Berat kering tajuk (Gambar 2) yang terbesar dihasilkan oleh perlakuan C yaitu sebesar 29,57 g sedangkan berat kering tajuk terendah dihasilkan oleh perlakuan A yaitu sebesar 2,28 g. Kedua perlakuan kombinasi menghasilkan berat kering tajuk berturut-turut sebesar 2,94 g dan $3,05 \mathrm{~g}$.

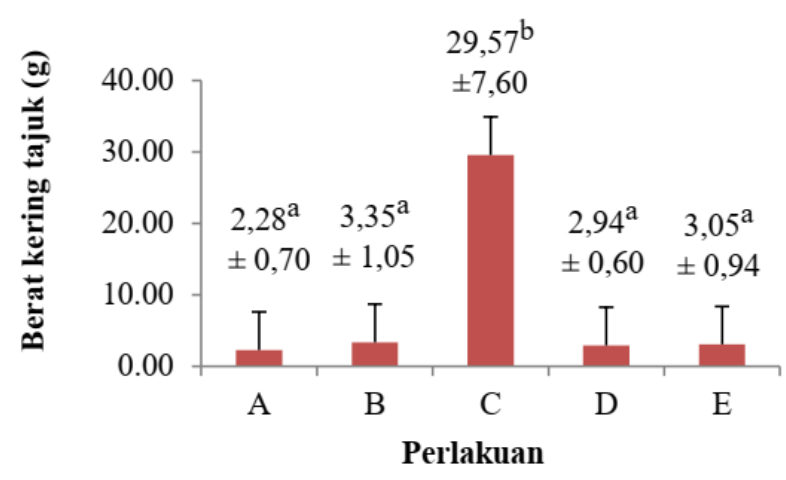

Gambar 2. Rata-rata berat kering tajuk. A. Tanah steril/kontrol. B. Tanah steril dan 50 spora Glomus sp. C. Tanah steril dan $2 \mathrm{~g}$ pupuk anorganik $\mathrm{CPN} \mathrm{KNO}_{3}$ Merah. D. Tanah steril, $5 \mathrm{~mL} T$. viride dan 50 spora Glomus sp. E. Tanah steril, $10 \mathrm{~mL}$ T.viride dan 50 spora Glomus sp.

Berat kering akar terbesar yaitu 7,87 g dihasilkan oleh perlakuan $\mathrm{C}$ sedangkan yang terkecil yaitu 1,15 g dihasilkan oleh perlakuan A (Gambar 3). Kedua perlakuan kombinasi $T$. viride dan FMA terlihat masih lebih rendah dibandingkan perlakuan $\mathrm{C}$ dan perlakuan $\mathrm{B}$.

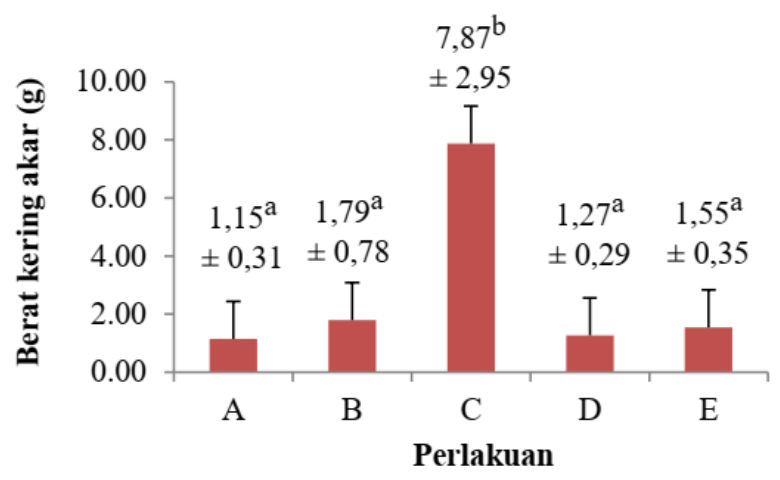

Gambar 3. Rata-rata berat kering akar. A. Tanah steril/kontrol. B. Tanah steril dan 50 spora Glomus sp. C. Tanah steril dan $2 \mathrm{~g}$ pupuk anorganik $\mathrm{CPN} \mathrm{KNO}_{3}$ Merah. D. Tanah steril, $5 \mathrm{~mL} T$. viride dan 50 spora Glomus sp. E. Tanah steril, $10 \mathrm{~mL}$ T.viride dan 50 spora Glomus sp.

\section{Jumlah dan berat buah}

Perlakuan C menghasilkan rata-rata jumlah buah terbanyak (28 buah) (Gambar 4). Pemberian pupuk anorganik yang mendukung pertumbuhan vegetatif mengakibatkan pertumbuhan generatif tanaman berjalan dengan optimal yang ditunjukkan dengan jumlah buah serta berat basah dan berat kering buah cabai rawit yang tinggi. 


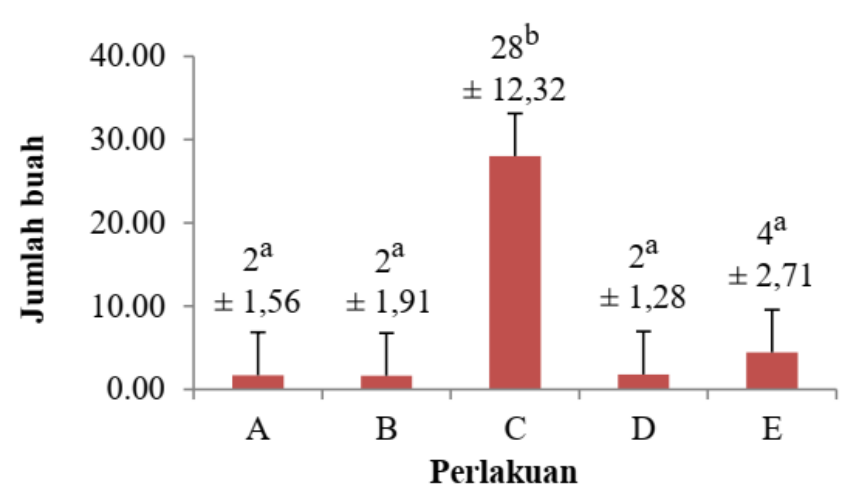

Gambar 4. Rata-rata jumlah buah cabai rawit. A. Tanah steril/kontrol. B. Tanah steril dan 50 spora Glomus sp. C. Tanah steril dan $2 \mathrm{~g}$ pupuk anorganik $\mathrm{CPN} \mathrm{KNO}_{3}$ Merah. D. Tanah steril, $5 \mathrm{~mL}$ T. viride dan 50 spora Glomus sp. E. Tanah steril, $10 \mathrm{~mL}$ T.viride dan 50 spora Glomus sp.

Rata-rata keseluruhan berat basah buah tertinggi ada pada perlakuan $\mathrm{C}$ yaitu sebesar 109,73 g (Gambar 5). Perlakuan C menghasilkan berat basah buah yang jauh lebih besar dibandingkan dengan perlakuan lain. Diantara kedua kombinasi pemberian T. viride dan Glomus sp. perlakuan E menghasilkan berat basah buah yang lebih besar.

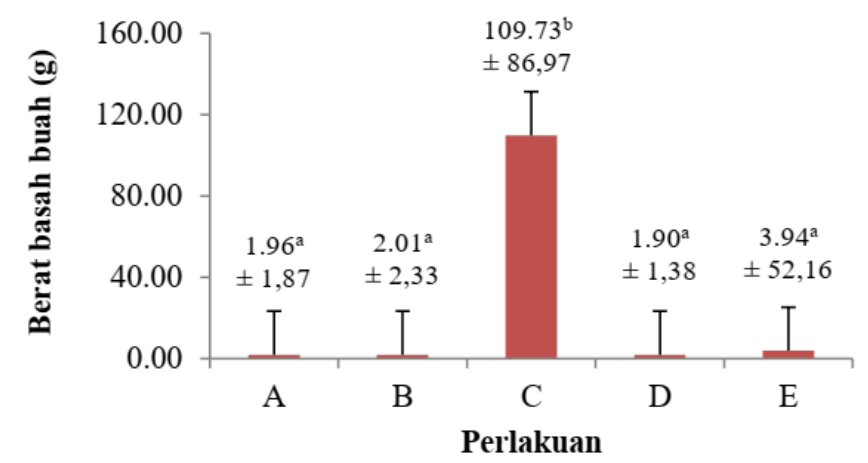

Gambar 5. Rata-rata berat basah buah. A. Tanah steril/kontrol. B. Tanah steril dan 50 spora Glomus sp. C. Tanah steril dan 2 g pupuk anorganik $\mathrm{CPN} \mathrm{KNO}_{3}$ Merah. D. Tanah steril, $5 \mathrm{~mL} T$. viride dan 50 spora Glomus sp. E. Tanah steril, $10 \mathrm{~mL}$ T.viride dan 50 spora Glomus sp.

Gambar 6. Menunjukkan perlakuan $\mathrm{C}$ menghasilkan rata-rata berat kering buah yang tertinggi diantara seluruh perlakuan yaitu sebesar 7,15 g. Sedangkan, berat kering buah terendah dihasilkan oleh perlakuan D sebesar 0,31 g. Diantara kedua kombinasi pemberian $T$. viride dan Glomus sp. perlakuan E menghasilkan rata-rata dan total berat kering buah yang lebih besar.

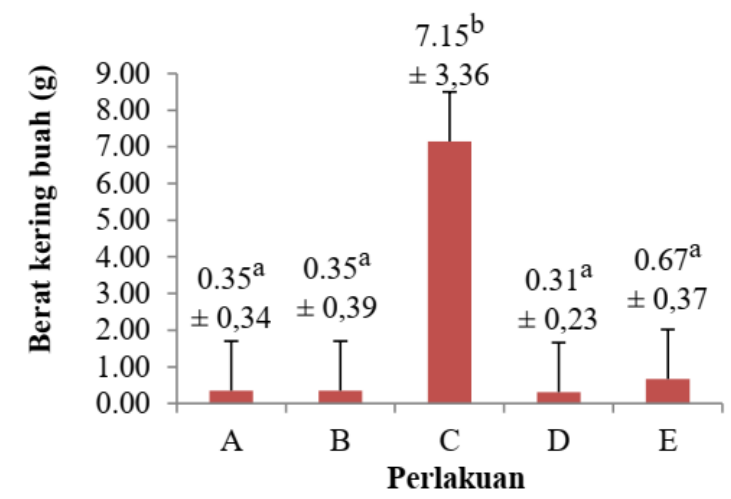

Gambar 6. Rata-rata berat kering buah. A. Tanah steril/kontrol. B. Tanah steril dan 50 spora Glomus 
sp. C. Tanah steril dan $2 \mathrm{~g}$ pupuk anorganik $\mathrm{CPN} \mathrm{KNO}_{3}$ Merah. D. Tanah steril, $5 \mathrm{~mL} T$. viride dan 50 spora Glomus sp. E. Tanah steril, $10 \mathrm{~mL}$ T.viride dan 50 spora Glomus sp.

\section{Persentase kolonisasi FMA}

Berdasarkan penghitungan jumlah kolonisasi FMA Glomus sp. pada masing-masing perlakuan (Gambar 7) diperoleh hasil yang menunjukkan kolonisasi tidak ditemukan pada perlakuan A dan C. Sedangkan pada perlakuan B, D dan E kolonisasi FMA pada akar tanaman secara berturut-turut sebesar $86,67 \% ; 83,58 \%$ dan $70,22 \%$. Berdasarkan criteria kolonisasi perlakuan B dan D termasuk ke dalam criteria kolonisasi sangat tinggi.

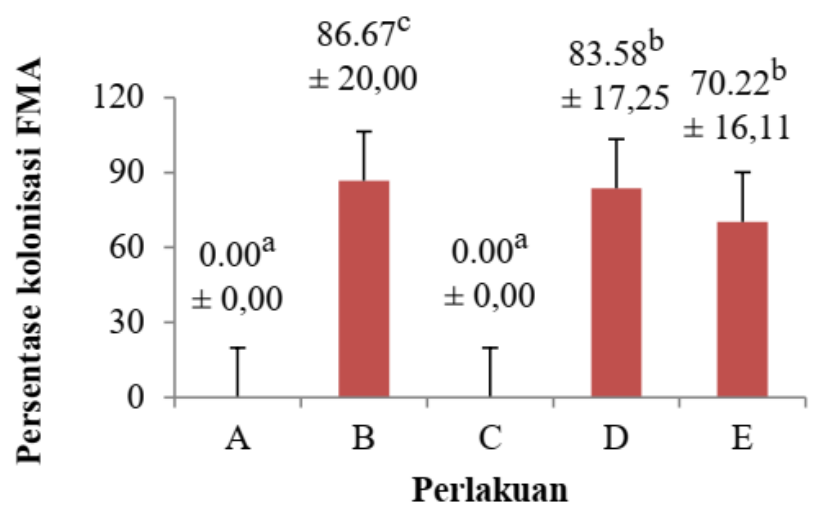

Gambar 7 Persentase kolonisasi FMA. A. Tanah steril/kontrol. B. Tanah steril dan 50 spora Glomus sp. C. Tanah steril dan $2 \mathrm{~g}$ pupuk anorganik CPN $\mathrm{KNO}_{3}$ Merah. D. Tanah steril, $5 \mathrm{~mL} T$. viride dan 50 spora Glomus sp. E. Tanah steril, $10 \mathrm{~mL}$ T.viride dan 50 spora Glomus sp.

\section{Pembahasan \\ Tinggi tanaman}

Penambahan pupuk anorganik CPN 15-0-14 $\mathrm{KNO}_{3}$ Merah diduga mampu menunjang pertumbuhan tanaman cabai rawit. Pupuk anorganik yang digunakan mengandung unsur hara seperti $\mathrm{N}$ yang berperan dalam pembentukan sel dan jaringan tanaman serta pembentukan klorofil, $\mathrm{K}$ yang berperan dalam proses fisiologis tanaman dan memperkuat ketahanan tanaman, natrium yang berperan dalam keseimbangan ion dan boron yang merangsang pertumbuhan akar dan buah. Hal ini sesuai dengan pendapat Nasrullah (2015) bahwa pupuk menambah banyak nutrisi di dalam media tanam sehingga meningkatkan pertumbuhan tanaman. Lingga \& Marsono (2004) menambahkan bahwa kandungan nitrogen akan meningkatkan pertumbuhan vegetatif tanaman. Pemberian jamur T. viride dan FMA belum menunjukkan hasil yang lebih tinggi dari pada pemberian pupuk anorganik, namun berpotensi menyokong pertumbuhan dan perkembangan tanaman melalui kolonisasi dengan perakaran tanaman yang membantu penyerapan unsur hara. Hal ini didukung oleh pernyataan Hartoyo dkk. (2015) bahwa hifa FMA dapat membantu penyerapan unsur hara yang tidak terjangkau oleh akar.

\section{Berat kering tanaman (tajuk dan akar)}

Penambahan unsur hara oleh pupuk anorganik dapat meningkatkan berat kering tajuk dan akar tanaman umur 120 hari. Putriantari \& Santoso (2014) menyatakan ketersediaan hara yang melimpah dapat menunjang pertumbuhan cabang dan akar pada tanaman. Hal ini didukung Siahaan dkk. (2018) yang menyatakan bahwa kandungan unsur hara $\mathrm{N}$ dari pemberian pupuk NPK pada media tanam dapat meningkatkan pertumbuhan cabang dan akar yang berdampak pada peningkatan berat kering tanaman. Penambahan T. viride dan FMA menghasilkan berat tajuk dan akar yang lebih rendah, namun kedua jamur ini dapat mendukung pertumbuhan tanaman cabai rawit melalui hifa yang membantu meningkatkan dan menyerap unsur hara. Berdasarkan hasil uji analisis faktor fisika dan kimia tanah sampel 
penelitian ini, pemberian $T$. viride dan FMA meningkatkan ketersediaan unsur $\mathrm{P}$ dan $\mathrm{K}$ di dalam tanah. Hartoyo dkk. (2015) melaporkan pemberian FMA dapat meningkatkan berat kering akar pegagan. Hal ini didukung oleh Azamri et al. (2011) yang menyatakan bahwa pemberian Trichoderma spp. dapat meningkatkan jumlah dan lebar daun.

\section{Jumlah dan berat buah}

Jumlah produksi buah yang lebih banyak, dapat meningkatkan berat pada buah cabai rawit. Adanya penambahan unsur hara dari pupuk anorganik pada perlakuan $\mathrm{C}$ meningkatkan ketersediaan nutrisi yang dapat dimanfaatkan oleh tanaman sehingga dapat mendukung pertumbuhan dan perkembangan tanaman cabai rawit. Penambahan $T$. viride yang belum menunjukkan hasil optimal terhadap cabai rawit dapat disebabkan oleh faktor luar yang mempengaruhinya (Yudha dkk. 2016). Jumlah spora FMA dan suspensi T. viride yang digunakan juga dapat menjadi salah satu faktor yang mempengaruhi hasil pada penelitian ini. Hal ini didukung oleh penelitian Abror \& Maulidin (2015) pada tanaman cabai rawit yang menggunakan $1 \mathrm{~kg}$ tanah dengan kandungan spora FMA sekitar 20 spora/g tanah. Valentine dkk. (2017) menyatakan bahwa pemberian Trichoderma spp. yang berpotensi meningkatkan pertumbuhan dan perkembangan tanaman adalah pada dosis $15 \mathrm{~g} \mathrm{tan}^{-1}$.

Perbedaan berat kering buah pada masing-masing perlakuan dapat disebabkan oleh perbedaan akumulasi kandungan di dalam buah dan biji (Emir dkk. 2017). Meskipun pemberian pupuk anorganik menunjukkan hasil yang tertinggi, kombinasi $10 \mathrm{~mL} T$. viride dan 50 spora FMA Glomus sp. mampu menghasilkan jumlah buah, berat basah dan berat kering buah yang lebih tinggi dibanding dengan kontrol. Penyerapan unsur hara oleh tanaman dibantu dengan adanya perpanjangan hifa jamur, sehingga nutrisi yang tidak terjangkau oleh akar dapat diserap tanaman. Menurut Seema \& Garampalli 2015 pemberian tiga jenis FMA meningkatkan berat kering pada tanaman lada.

\section{Persentase kolonisasi FMA}

Besarnya tingkat infeksi FMA dipengaruhi oleh jenis dari FMA yang digunakan, karakteristik tanaman serta kondisi lingkungan seperti suhu, kelembaban dan kandungan unsur hara tanah (Wicaksono dkk. 2014). Perbedaan genetik juga turut mempengaruhi kemampuan adaptasi dari suatu varietas terhadap lingkungan tumbuh (Dermawan dkk. 2018). Tidak adanya kolonisasi FMA mungkin terjadi karena tanpa penambahan FMA tidak akan terbentuk asosiasi pada akar tanaman sehingga pada pengamatan tidak ditemukan ciri adanya kolonisasi seperti adanya vesikel, spora, arbuskula ataupun hifa eksternal (Nurmasyitah \& Khairuna 2017). Kolonisasi yang lebih rendah pada perlakuan kombinasi dengan T. viride diduga karena keberadaan T.viride membantu meningkatkan nutrisi di dalam tanah sehingga kolonisasi FMA menurun. Hal ini didukung oleh Saputra dkk. (2015) yang menyatakan peningkatan kolonisasi FMA terjadi pada kondisi lingkungan dengan kadar unsur hara yang rendah.

\section{Ucapan Terima Kasih}

Penulis pertama (WPS) dan penulis kedua (MRD) mengucapkan terima kasih kepada penulis ketiga (MWP) yang telah mendanai penelitian ini.

\section{Pustaka}

Abror M, Mauludin M. 2015 - Pengaruh pemberian mikoriza vesicular arbuskula terhadap efisiensi penyerapan fosfat pada pertumbuhan dan produksi cabai rawit (Capsicum frutescens L.). Nabatia Journal of Agricultural Science 12(1), 51-62.

Azamri R, Hajieghrari B, Giglou A. 2011 - Effect of Trichoderma isolates on tomato seedling growth response and nutrient uptake. African Journal of Biotechnology 10(31), 5850-5855. 
Dermawan R, Farid MBDR, Ridwan I, Syarifuddin R. 2018 - Aplikasi pupuk boron pada media tanam terhadap pertumbuhan dan produksi varietas cabai besar (Capsicum annuum L.). J. Floratek 13(1), 37-48.

Emir MN, Aini N, Koesriharti. 2017 - Pengaruh aplikasi pupuk organic terhadap pertumbuhan dan hasil tanaman cabai merah (Capsicum annuum L.). Jurnal Produksi Tanaman 5(11), 1845-1850.

Gusnawaty HS, Taufik M, Triana L, Asniasih. 2014 - Karakterisasi morfologi Trichoderma spp. Indigenus Sulawesi Tenggara. Jurnal Agroteknos 4(2), 87-93.

Hartoyo B, Trisilawati O, Ghulamahdi M. 2015 - Tanggap pertumbuhan dan biomasa pegagan (Centella asiatica (L) Urban) pada aplikasi fungi mikoriza arbuskular dan pemupukan di tanah andosol. Buletin Penelitian Tanaman Rempah dan Obat 26 (2), 87-98.

Kormanik PP and Mc.Graw AC. 1982 - Quantification of Vesicular-Arbuscular Mycorrhizae in plant roots. In N.C. Schenck (Ed). Methods and Principles of Mycorrhizal Research. The American Phytopathological Society. St. Paul.

Lingga P, Marsono 2004 - Petunjuk Penggunaan Pupuk. Penebar Swadaya, Jakarta.

Musfal M. 2010- Potensi cendawan mikoriza arbuskula untuk meningkatkan hasil tanaman jagung. Jurnal Penerlitian dan Pengembangan Pertanian. 29 (4), 154-158.

Nadhifah YM, Hastuti US, Istamar S. 2016 - Isolasi, karakterisasi, dan identifikasi mikoflora dari rizosfer tanah pertanian tebu (Saccharum officinarum L.) sebagai bahan ajar Kingdom Fungi untuk siswa kelas X SMA. Jurnal Pendidikan 1 (10), 2023-2030.

Nasrullah, Nurhayati, Marliah A. 2015 - Pengaruh dosis pupuk NPK (16:16:16) dan mikoriza terhadap pertumbuhan bibit kakao (Theobroma cacao L.) pada media tumbuh subsoil. Jurnal Agrium 12 (2), 56-64.

Nurmasyitah, Khairuna. 2017 - Aplikasi pupuk NPK dan fungi mikoriza arbuskular (FMA) terhadap $\mathrm{P}$ tersedia tanah, serapan $\mathrm{P}$ dan pertumbuhan bibit lada local aceh pada media tanah inceptisols. J. Floratek 12 (2), 62-74.

Putriantari M, Santoso. 2014 - Pertumbuhan dan kadar alkaloid tanaman leunca (Solanum americatum Miller). pada beberapa dosis nitrogen. Jurnal Hortikultura Indonesia 5 (3), 175-182.

Prasetyawati CA, Dania ASR. 2017 - Tahapan perbanyakan jamur Trichoderma harzianum dengan media dedak dan aplikasinya pada tanaman murbei (Morus sp.). Info Teknis Eboni 14 (1), 1-9.

Rachman E, Hani A. 2014 - Pola agroforestry sengon (Falcataria moluccana L.) dan cabai merah keriting di dataran tinggi Ciamis Jawa Barat. Jurnal Penelitian Agroforestry 2 (1), 35-44.

Salampessy MN, Mardji D, Sutisna M. 2008 - Pengaruh jamur endomikoriza, intensitas cahaya dan kandungan air tanah terhadap pertumbuhan semai Gaharu (Aquilaria malaccensis Lamk.) di persemaian. Jurnal Kehutanan Tropika Humida 1(1), 6373.

Saputra B, Linda R, Lovadi I. 2015 - Jamur mikoriza vesicular arbuskular (MVA) pada tiga jenis tanah rhizosfer tanaman pisang nipah (Musa paradisiacal L.var.nipah) di Kabupaten Pontianak. Jurnal Protobiont 4 (1), 160-169.

Schüßler A, Walker C. 2010 - The Glomeromycota. A Species List with New Families and New Genera. http://www.amf-phylogeny.com/(accessed 6 November 2019).

Seema HS, Garampalli RH. 2015 - Effect of arbuscular mycorrhizal fungi on growth and biomass enhancement in Piper longum L. (Piperaceae). International Journal of Current Microbiology and Applied Sciences 4 (1), 11-18.

Setyadi IMD, Artha IN, Wirya GNAS. 2017- Efektifitas pemberian kompos Trichoderma sp. Terhadap pertumbuhan tanaman cabai (Capsicum annum L.). E-Jurnal 
Agroekoteknologi Tropika 6 (1), 21-30.

Siahaan CD, Sitawati, Heddy S. 2018 - Uji efektifitas pupuk hayati pada tanaman cabai rawit (Capsicum frutescens L.). Jurnal Produksi Tanaman 9 (6), 2053-2061.

Subiksa IGM. 2002 - Pemanfaatan Mikoriza untuk Penanggulangan Lahan Kritis. Makalah Falsafah Sains (PPs 702). Bogor, Institut Pertanian Bogor.

Syahputra MH, Anhar A, Irdawati. 2017 - Isolasi Trichoderma spp. dari beberapa rizosfer tanaman Padi asal solok. Journal Biosains 1 (2), 97-105.

Valentine K, Herlina N, Aini N. 2017 - Pengaruh pemberian mikoriza dan Trichoderma sp. terhadap pertumbuhan dan hasil produksi benih melon hibrida (Cucumis melo L.). Jurnal Produksi Tanaman 5 (7), 1085-1092.

Warisno, Dhana K. 2010 - Peluang Usaha dan Budidaya Cabai. PT. Gramedia Pustaka Utama. Jakarta.

Wicaksono MI, Rahayu M, Samanhudi. 2014 - Pengaruh pemberian mikoriza dan pupuk organik terhadap pertumbuhan bawang putih. Caraka Tani: Journal of Sustainable Agriculture 29 (1), 35-44.

Yudha MK, Soesanto L, Mugiastuti E. 2016 - Pemanfaatan empat isolat Trichoderma sp. untuk mengendalikan penyakit akar gada pada tanaman Caisin. Jurnal Kultivasi 15 (3), 143-149. 